\title{
O NOVO PARADIGMA DE RACIONALIDADE DO DIREITO: A CENTRALIDADE DO CONCEITO DE PESSOA NO ORDENAMENTO JURÍDICO ATUAL
}

\section{Anelise Domingues Schuler ${ }^{1}$}

\section{INTRODUÇÃO}

A partir da segunda metade do século XX, percebe-se uma tendência institucional nos países de tradição jurídica romano-germânica no sentido de recompor a ordem democrática e de atribuir um conteúdo substancial ao Direito. Evidentemente, a adoção dessa nova concepção de Direito não ocorreu de forma uniforme nos diferentes países, pois sua necessidade foi surgindo conforme as peculiaridades históricas de cada um. Assim, verificou-se na Europa Continental, com a derrota do nazismo e do fascismo, no final dos anos 1940; na Península Ibérica, após o franquismo e o salaza- rismo, no fim dos anos 1970; no Leste Europeu, com o término dos regimes totalitários de esquerda, e na América do Sul, com o declínio das ditaduras, após os anos 1980.

Como decorrência de momentos político-institucionais turbulentos e desrespeitosos para a humanidade, tal concepção consagra, como seu primeiro fundamento e como seu último fim, o valor da dignidade da pessoa humana, mantendo-o subjacente a todo ordenamento jurídico, sobretudo às normas de direitos fundamentais. Constituída sobre uma base democrática, pluralista e axiológica, a concepção de Direito adotada a partir da segunda metade do século XX reflete

1 Mestre em Direito pelo Programa de Pós-Graduação em Direito da Universidade Federal do Rio Grande do Sul (UFRGS).E-mail: aneliseschuler@hotmail.com. Currículo Lattes: http://lattes.cnpq.br/8959455107602191. 
uma realidade social, política e econômica complexa, demandando o constante esforço dos juristas no sentido de compreendê-la, mantê-la e atualizá-la, em face das contínuas mudanças decorrentes dessa realidade.

A Constituição da República Federativa do Brasil de 1988 assumiu essa tendência, destacando a dignidade da pessoa humana como fundamento do Estado Democrático de Direito Brasileiro, em seu artigo $1^{\circ}$, inciso III. Tal opção exige grandes modificações no ordenamento jurídico brasileiro, sobre as quais se deve refletir e discutir a fim de encontrar o melhor modo de implementá-las, dimensionando as suas consequências.

Um dos maiores impactos decorrentes dessa nova concepção de Direito impõe-se sobre o Direito Privado. Alterou-se a relação existente entre o Direito Constitucional e o Direito Privado, pois os valores estabelecidos na Constituição, por consenso social, devem transcender para o conteúdo das normas de Direito Privado. Tal fato desencadeou um processo de reconstrução ou, pelo menos, de releitura dos institutos de Direito Privado, no qual o reconhecimento da centralidade do conceito de pessoa como elemento da relação jurídica assume um aspecto principal.

A relevância do tema impõe-se em razão da importância atribuída aos direitos fundamentais, na concepção de Direito vigente a partir da segun- da metade do século XX. Seu principal objetivo é realizar a dignidade da pessoa humana através do respeito e da concretização dos direitos fundamentais. Nesse sentido, o reconhecimento da centralidade do conceito de pessoa, no âmbito do Direito Privado, representa um passo significativo. Por outro lado, a relevância do tema afirma-se na necessidade de definirem-se os limites da influência do Direito Constitucional sobre o Direito Privado, sob pena de descaracterizar-se o segundo, acabando com um âmbito jurídico imprescindível ao desenvolvimento da personalidade e da liberdade das pessoas. Ademais, tal relevância justifica-se diante da premência de estabelecer-se o modo pelo qual operacionalizar a influência das normas constitucionais, sobretudo as definidoras dos direitos fundamentais, sobre as normas de Direito Privado a fim de garantir-se a segurança jurídica.

O reconhecimento da centralidade do conceito de pessoa no ordenamento jurídico atual é um dos reflexos da mudança no paradigma de racionalidade jurídica que alterou a concepção de Direito vigente durante o século XIX, dando origem a uma nova concepção de Direito para o século XX.

Assim, no desenvolvimento deste trabalho, apresentam-se cada uma dessas concepções e apontam-se as razões para tal mudança, uma vez que, para conhecer a situação atual de 
um sistema jurídico, faz-se necessário conhecer, ainda que brevemente, seu desenvolvimento histórico e as influências que marcaram suas opções políticas e jurídicas. Partindo-se desse contexto, desenvolve-se a centralidade do conceito de pessoa no ordenamento jurídico atual, enfatizando-se seus reflexos sobre o Direito Privado.

Conforme referido anteriormente, o reconhecimento da centralidade do conceito de pessoa ocorreu em diversos países, em momentos históricos diferentes. Dessa forma, adotar-se-ão, para seu desenvolvimento, generalizações quanto às diferentes fases desse processo a fim de traçar seu panorama.

\section{CONCEPÇÃO DE DIREITO VIGENTE DURANTE O SÉCULO XIX}

A concepção de Direito vigente durante o século XIX desenvolveu-se no seio do Estado Liberal, refletindo, assim, os aspectos ideológicos, sociais e políticos desse período. Ela iniciou com a publicação do Code Civil, na França (1804), e terminou com o início da Segunda Guerra Mundial. Identifica-se com a consolidação de uma ordem jurídica liberal e individualista, decorrente da representatividade política de uma única classe social: a burguesia.

O ordenamento jurídico desse período desenvolveu-se sob a égide do princípio da legalidade, segundo o qual a lei possuía superioridade frente aos demais atos normativos, inclusive em relação à Constituição (Zagrebelsky, 1999, p. 31). O Direito reduzia-se à lei, considerada sua forma mais perfeita por possuir duas características peculiares em relação aos demais atos normativos: a generalidade e a abstração. Através da generalidade, a lei disciplinava o comportamento de um grupo indeterminado de pessoas, realizando a igualdade formal (Bobbio, 1995b, p. 231-232). Através da abstração, a lei determinava um padrão para as ações das pessoas, viabilizando a segurança jurídica (Bobbio, 1995b, p. 231-232).

Tal princípio desdobrava-se em três diferentes aspectos: (1) quanto ao Poder Executivo, a Administração deveria realizar suas atividades exatamente nos termos previstos na lei; (2) quanto ao Poder Judiciário, do mesmo modo, os juízes deveriam aplicar estritamente os comandos legais sem espaço algum para construções jurisdicionais; (3) quanto aos cidadãos, por outro lado, preponderava a liberdade para fazer tudo que não fosse proibido pela lei.

Através desses desdobramentos, o princípio da legalidade garantia a coerência da ordem jurídica decorrente da concepção de Direito do século XIX. A burguesia, única classe social com representatividade política nesse momento, elaborava as leis na 
Câmara Representativa e o Executivo, bem como o Judiciário somente as aplicavam (Zagrebelsky,1999, p. 3031). O Direito sustentava-se por uma unidade pressuposta, os valores e os princípios do Estado Liberal, os quais eram considerados tão fundamentais que não necessitavam de expressão nos textos jurídicos.

A concepção de Direito dessa época identificava-se com o movimento positivista quanto ao método, à teoria e à ideologia jurídica. Como método, o positivismo jurídico preconizava uma abordagem avalorativa, segundo a qual o Direito seria apenas um conjunto de fatos, fenômenos ou dados sociais, prescindindo de ser bom ou mau, de ser um valor ou um desvalor. Enquanto teoria, o positivismo jurídico descrevia o Direito com base: (1) na coatividade, (2) na legislação como fonte preponderante, (3) na norma jurídica como imperativo, (4) no ordenamento coerente e completo e (5) na interpretação mecanicista. Por fim, como ideologia, o positivismo ético declarava que o Direito possuía um valor enquanto tal, totalmente independente do seu conteúdo (Bobbio, 1995b, p. 131-132).

O ideal jurídico descrito até aqui se refletia, sobretudo, no Código Civil, o qual representava a vontade positiva do legislador dotada de generalidade, de abstração, de sistematicidade e de plenitude para ser imposta em todo o território do Estado (Zagrebelsky,
1999, p. 32). Além dessas características formais, o Código Civil consagrava, como seu principal objetivo, o pleno desenvolvimento da personalidade individual (Larenz, 1978, p. 56.). Para tanto, fundamentava-se em um modelo de autonomia privada, descomprometido com eventuais consequências sociais, produzindo uma liberdade meramente formal embasada em uma igualdade também formal (Hesse, 1995, p. 79). Priorizava-se o indivíduo em detrimento à sociedade na qual ele vivia (Bobbio, 1995a, p. 25).

Nesse contexto, o contrato era considerado o principal instrumento da autonomia privada, permitindo que as pessoas decidissem livremente sobre os assuntos que lhe afetavam diretamente. Ademais, a propriedade era o principal meio de realização da personalidade, uma vez que as pessoas precisavam das coisas para suprirem as suas necessidades e, tendo consciência de sua individualidade, buscavam construir seu próprio entorno e dispor das coisas por si mesmas (Larenz, 1978, p. 51-53).

Nesse período, o Direito Constitucional e o Direito Civil eram considerados ramos autônomos e incomunicáveis do Direito, reproduzindo a nítida separação entre o Estado e a sociedade própria do liberalismo burguês. A Constituição era um diploma político que determinava a organização fundamental do Estado e as liberdades públicas - não possuía qualquer 
eficácia jurídica. Por outro lado, o Código Civil era um diploma jurídico responsável por estabelecer as linhas gerais da ordem jurídica e por disciplinar a vida privada dos indivíduos (Wieacker, 1993, p. 628).

\section{CRISE DA CONCEPÇÃO DE DIREITO VIGENTE DURANTE O SÉCULO XIX}

A concepção de Direito do século XIX foi abalada pela desconstituição da base política, social e econômica que lhe dava sustentação. Os principais acontecimentos para o desencadeamento desse processo foram: (1) o desenvolvimento do pluralismo político, que quebrou a coerência jurídica fundamentada na representatividade política exclusiva da burguesia e (2) a ascensão dos regimes totalitários, cujo resultado levou ao questionamento do método, da teoria e da ideologia jurídica vigentes. A seguir, investigam-se cada um desses fatores.

As demais classes sociais ganharam expressão em razão da institucionalização do voto universal, pelo qual puderam expressar seus interesses no plano político. Passou-se, portanto, da unidade para o pluralismo político (Wieacker, 1993, p. 628). Tal realidade tornou-se emblemática para a sociedade do século XX por compor-se de uma grande diversidade de grupos sociais com interesses, ideo- logias e projetos diferentes, sem que nenhum deles tivesse força suficiente para ser exclusivo ou dominante (Zagrebelsky,1999, p. 13).

O surgimento do pluralismo político e social afetou irremediavelmente a generalidade e a abstração da lei, pois o processo legislativo transformou-se na conclusão de um processo político. No momento em que algum dos diferentes grupos sociais que disputavam o poder político alcançava força suficiente para impor seus interesses aos demais, tomava as providências necessárias para mudar a legislação. O ordenamento jurídico marcou-se pela ocasionalidade e pela heterogeneidade dos valores e dos interesses expressos na lei (Zagrebelsky, 1999, p. 37).

Por conseguinte, desfez-se a homogeneidade política e social que sustentava a ordem jurídica do século XIX. A unidade jurídica representada pelo Código deu lugar a uma gama de legislação extravagante voltada a proteger juridicamente os interesses dos diferentes grupos sociais. O pluralismo social levou à falência dos valores burgueses e à quebra da lógica do ordenamento jurídico.

Tal fato impulsionou a construção de uma base teórica democrática e pluralista para o Estado apoiada em postulados racionais lógicoformais, vazios de conteúdo material valorativo, a fim de serem aceitos por todas as posições ideológicas. Essa 
ausência de valores na ordem jurídica levou ao esvaziamento do Direito sob o ponto de vista político-constitucional, pois não definia as funções e os fins do Estado, nem a natureza da lei. Dessa forma, permitiu-se a ascensão de ideologias políticas contrárias à democracia e ao pluralismo, que se valeram do instrumental juspolítico do Estado de forma alternativa, com o objetivo de derrubá-lo para implantar um regime totalitário (Souza Junior, 2002, p. 101).

O movimento positivista, dominante durante o século XIX e a primeira metade do século XX, não impôs resistência alguma à ascensão dos regimes totalitários. Pelo contrário, ao defender um ordenamento jurídico formal, isento de valores, ofereceu as condições jurídicas próprias ao estabelecimento desses. Tal movimento reduziu todo o conteúdo do Direito aos termos da lei, desenvolvendo uma concepção formalista, conforme a qual o Direito é o que vige como tal em uma determinada sociedade, são as normas que se fazem valer por meio da força. Assim, a validade do Direito se fundaria em critérios que concernem, unicamente, a sua estrutura formal (Bobbio, 1995b, p. 131132), prescindindo de seu conteúdo.

Ademais, no âmbito ideológico, o positivismo defendia que o Direito possuía um valor em si mesmo, independentemente de seu conteúdo, por ser o meio necessário para a realização da ordem. Tal entendimento reforçou o formalismo, pois, ainda que se impusesse um fim superior ao Direito, como uma ordem justa, a justiça resumir-se-ia à legalidade (Bobbio, 1995b, p. 231).

As experiências vividas durante a vigência dos regimes totalitários acarretaram um completo descrédito em relação à concepção de Direito vigente durante o século XIX. Estava evidente a inaptidão dessa ordem jurídica para a proteção dos direitos humanos. Despertou-se, então, a consciência ética do Ocidente, adormecida pela vigência do positivismo radical (Souza Junior, 2002, p. 102). Necessitava-se, mais do que nunca, revisar as bases filosóficas do Estado, dando significado substancial ao Direito.

\section{CONCEPÇÃO DE DIREITO VIGENTE A PARTIR DA SEGUNDA METADE DO SÉCULO XX}

A concepção de Direito vigente a partir da segunda metade do século XX desenvolveu-se em razão do vácuo ideológico e político que assolou a Europa com o término da Segunda Guerra Mundial. Ela representou a revisão da fundamentação filosófica do Estado e do Direito e a reconstrução da ordem política democrática, sendo marcante para a ordem jurídica da atualidade. 
As atrocidades praticadas pelos regimes totalitários demonstraram que o primeiro limite a ser imposto aos detentores do poder concerne à proteção da essência humana. Dessa forma, colocou-se "antes e acima de qualquer outra exigência da ordem jurídica, a proteção da dignidade existencial da pessoa humana" (Souza Junior, 2002, p. 106). O Direito Constitucional passou a assumir a dignidade da pessoa humana como seu fundamento e como sua finalidade (Souza Junior, 2002, p. 106). Consequentemente, a dignidade da pessoa humana foi expressamente reconhecida como fundamento do Estado de Direito pelas Constituições de vários países, como Itália (art. $3^{\circ}$ da Constituição de 1947), Alemanha (art.1 ${ }^{\circ}$, alínea I da Lei Fundamental de Bonn de 1949), Grécia (art. $7^{\circ}$ da Constituição de 1975), Portugal (art. $1^{\circ}, 13, \S 1^{\circ}$ e 26, §2 da Constituição de 1976), Espanha (art. 10, §1 $1^{\circ}$ da Constituição de 1978) e Brasil (art. $1^{\circ}$, III da Constituição de 1988).

Nesse período, os pluralismos social e político correspondiam a uma realidade consolidada, impondo dificuldades para a unidade e para a coerência do ordenamento jurídico. Então, percebeu-se a necessidade de submeter às normas jurídicas não apenas as atividades do Executivo e do Judiciário, mas, também, as do Legislativo. Nesse sentido, as Constituições assumiram uma nova posição no ordenamento jurídico, pois diante da heterogeneidade do processo legislativo acompanhada da superabundância de leis, os textos constitucionais transformaram-se em instrumentos capazes de evitar a desordem e a incoerência do ordenamento (Zagrebelsky, 1999, p. 39-40).

Para tanto, as Constituições passaram a prever um conjunto de princípios e valores radicado no aspecto universal da pessoa humana, sobre os quais existiria um consenso social amplo. Tais valores elevaram a Constituição a um nível normativo superior do ordenamento jurídico, institucionalizando sua supremacia.

Dessa forma, modificou-se, radicalmente, a posição ocupada pelas leis no ordenamento jurídico. Pela primeira vez, essas foram submetidas a uma relação de adequação e de subordinação a um nível normativo mais alto - a Constituição (Zagrebelsky, 1999, p. 34). Desse modo, além da Constituição ser a norma reguladora da vida política, passou a ser (1) o repositório das normas jurídicas supremas; (2) o fundamento de validade de todo ordenamento jurídico; (3) a cabeça de capítulo de todos os ramos do Direito; e (3) o paradigma para a conformação de todas as normas infraconstitucionais, sob pena de invalidade (Souza Junior, 2002, p. 105).

A concepção de Direito estabelecida no século $\mathrm{XX}$ demonstrou que a institucionalização de valores trans- 
cendentes é plenamente compatível com o pluralismo social e com a democracia, pois os valores reconhecidos devem ser abertos ao aspecto universal da pessoa (Souza Junior, 2002, p. 107). Quando há concordância quanto aos princípios gerais da convivência política e social a ponto desses serem consagrados em um nível normativo superior, o pluralismo não degenera em uma anarquia legislativa. O princípio da constitucionalidade coloca-se como mantenedor da unidade do ordenamento e da paz social (Zagrebelsky, 1999, p. 40).

Todavia, a eficácia dos valores constitucionais e, por conseguinte, a realização da supremacia da Constituição dependem de mecanismos jurídicos de proteção, capazes de conferir força normativa ao texto constitucional. Então, a partir da segunda metade do século XX, instituiu-se na Europa o controle de constitucionalidade adequado aos ordenamentos jurídicos de tradição romano-germânica.

A comparação entre a concepção de Direito vigente durante o século XIX e a concepção de Direito vigente a partir da segunda metade do século XX evidencia diferenças radicais entre elas. A nova concepção jurídica definiu-se em uma realidade política, social e econômica mais complexa que a anterior. Nesse sentido, ela suscita várias questões discutidas na atualidade, tais como descodificação, constitucionalização, judicialização da política, ativismo judicial, privatização do público e publicização do privado. Nesse contexto, passa-se a estudar, especificamente, a questão da centralidade do conceito de pessoa como elemento da relação jurídica e suas consequências, principalmente, para o Direito Privado.

\section{CENTRALIDADE DO CONCEITO DE PESSOA NO ORDENAMENTO JURÍDICO ATUAL}

A centralidade do conceito de pessoa, no ordenamento jurídico atual, é o resultado dessa mudança no paradigma de racionalidade jurídico realizada pela concepção de Direito vigente a partir da segunda metade do século XX. O ordenamento jurídico deixou de ser uma ordem meramente formalista. Optou-se por conferir conteúdo substancial ao Direito, radicando-o na dignidade da pessoa humana como seu fim último.

Enquanto conceito filosófico, a dignidade da pessoa humana tem suas origens remotas fixadas tanto no pensamento clássico quanto no ideário cristão. Enquanto conceito jurídico, a dignidade da pessoa humana representa um valor constitucional subjacente a todo o ordenamento jurídico, sobretudo, às normas relativas aos direitos fundamentais. Possui um conteúdo axiológico muito forte, o qual 
dificulta a formulação de um conceito preciso e inequívoco. No entanto, na atualidade, seu reconhecimento e sua institucionalização, inevitavelmente, determinam diretrizes mínimas para a ordem jurídica.

Nesse sentido, o ordenamento jurídico parte do pressuposto de que cada ser humano possui um valor intrínseco, unicamente em razão de sua condição humana. O ser humano é considerado sob uma perspectiva relacional, segundo a qual é reconhecida sua individualidade, através da liberdade para fazer suas escolhas, bem como sua sociabilidade, pela imposição da responsabilidade e do respeito mútuo (Hesse, 1995, p. 87). Além disso, a construção de uma ordem jurídica albergada na dignidade da pessoa humana evidencia uma opção axiológica, que reforça o comprometimento desta com os direitos fundamentais, sobretudo com os direitos de liberdade, abrindo-a para um núcleo de valores mínimos estabelecidos por consenso, os quais garantem sua unidade, bem como a paz social.

Com efeito, partindo da dignidade da pessoa humana como valor subjacente a toda ordem jurídica, a concepção de Direito construída no século XX optou por constitucionalizar os direitos humanos, os direitos fundamentais, uma vez que estes constituiriam um núcleo consensual para a ordem social e política. Nes- se sentido, ampliou-se o conteúdo do Direito para além dos termos da lei, diferenciando-se os direitos humanos da legislação ordinária (Zagrebelsky, 1999). As normas relativas aos direitos humanos assumem diferentes significados no ordenamento jurídico. Em um aspecto subjetivo, elas representariam direitos jurídico-constitucionais básicos dos particulares. Em um aspecto objetivo, elas determinariam os conteúdos fundamentais da ordem jurídica (Hesse, 1998).

Atualmente, os direitos fundamentais previstos na Constituição são considerados princípios objetivos não apenas para o Direito Constitucional, mas para todo o ordenamento jurídico, impondo diretrizes. Tais preceitos fundamentais são decisivos para a atividade do legislador e para as instâncias aplicadoras do Direito, que devem considerar a influência desses na criação, na interpretação e na aplicação das normas jurídicas (Hesse, 1995, p. 57-58).

Nesse sentido, percebe-se que, em razão da mudança no papel desempenhado pela Constituição, a concepção de Direito estabelecida a partir da segunda metade do século XX alterou as relações entre o Direito Constitucional e o Direito Ordinário, fazendo com que os preceitos constitucionais transcendam para as normas infraconstitucionais. Dessa forma, o Direito Privado fica amplamente aberto às influências do Direito Constitucional. 
Evidentemente, essa relação revela-se complexa por se sobrepor ao Direito Privado - que determina a configuração das relações jurídicas e a decisão dos conflitos jurídicos - uma ordem de valores formada por normas amplas e indeterminadas, dificultando a determinação do seu conteúdo na aplicação aos casos concretos (Hesse, 1995, p. 59-60).

Assim, a aplicação mediata ou indireta dos preceitos constitucionais é a forma mais adequada às particularidades da sua realização nas relações jurídicas privadas, garantindo a clareza e a segurança jurídica. Nessa perspectiva, corresponde, constitucionalmente, ao legislador de Direito Privado a tarefa de transformar o conteúdo dos direitos fundamentais, de forma definida, clara e concreta, em direito imediatamente vinculante para as partes das relações jurídicas privadas. Por essa razão, cabe sobretudo ao legislador cuidar das múltiplas modificações decorrentes da influência dos direitos fundamentais sobre o Direito Privado (Hesse, 1995, p. 63-64).

Desse modo, diferencia-se um âmbito jurídico de um âmbito político no ordenamento. Os direitos fundamentais, principalmente os direitos de liberdade, são institucionalizados como patrimônio subjetivo individual, a ser atualizado pelo labor dos juízes. São totalmente isentos às incursões políticas. Já as leis são reconhecidas como instrumentos dos projetos políticos e jurídicos objetivos, nos quais as decisões políticas desempenham legitimamente o seu papel. Nesse sentido, a definição do conteúdo dos direitos fundamentais nas relações jurídicas de Direito Privado assume o caráter de opção política (Zagrebelsky, 1999, p. 58-60).

Obviamente, uma legislação materialmente diferenciadora, que determina os pressupostos e os efeitos da influência dos preceitos fundamentais sobre o Direito Privado, conduz a uma maior clareza, certeza e previsibilidade jurídicas. Todavia, na realização de sua tarefa, o legislador ordinário não poderá renunciar aos conceitos indeterminados e às cláusulas gerais. Dessa forma, os juízes devem concentrar seus esforços em interpretar o direito aplicável em conformidade com a Constituição; observar os direitos fundamentais como princípios objetivos na precisão de conceitos indeterminados e na interpretação de cláusulas gerais e investigar a compatibilidade da legislação com a Constituição (Hesse, 1995, p. 65-66).

Considerando-se as alterações qualitativas que a concepção de Direito desenvolvida a partir da segunda metade do século XX imprimiu no ordenamento jurídico, sobretudo nas relações entre o Direito Constitucional e o Direito Privado, passa-se a observar, especificamente, as mudanças ocorridas no Direito Privado. 


\section{REFLEXOS DA \\ CENTRALIDADE DO \\ CONCEITO DE PESSOA NO DIREITO PRIVADO}

A inter-relação entre o Direito Constitucional e o Direito Privado, decorrente da centralidade do conceito de pessoa, apresenta reflexos significativos, principalmente, no âmbito do Direito Civil. A concepção de Direito adotada no século XX desencadeou um processo de reconstrução ou, pelo menos, de releitura dos institutos do Direito Privado - desempenhado pela legislação extravagante, pela doutrina e pela jurisprudência - o qual impregnou as normas de Direito Privado com o conteúdo substancial da ordem jurídica.

Tal processo caracterizou-se pelo recuo perante o formalismo do sistema de Direito Privado, clássico do século XIX; pela relativização dos institutos de Direito Privado através do reconhecimento da sua função social; bem como pela vinculação ético-social desses institutos (Wieacker, 1993, p. 624). Para tanto, corresponde ao operador do Direito Privado (1) individualizar um sistema de Direito Civil mais harmonizado aos princípios fundamentais e, em especial, às necessidades existenciais da pessoa; (2) redefinir o fundamento e a extensão dos institutos jurídicos, evidenciando seus perfis funcionais, numa tentativa de revitalização de cada nor- ma à luz de um novo juízo de valor; e (3) verificar e adaptar as técnicas e as noções tradicionais, em um esforço de modernização dos instrumentos e, em especial, da teoria da interpretação (Perlingieri, 2001, p. 200).

Nesse contexto, o Direito Privado passou de uma ética individual da vontade e da liberdade para uma ética social da responsabilidade solidária. Deixou de atender somente a autodeterminação individual, para atender também a justiça social, assumindo um perfil tutelar e delimitador (Hesse, 1995, p. 73). Evidentemente, o Direito Privado permanece como o ramo do Direito responsável por determinar a configuração das relações jurídicas e a decisão dos conflitos jurídicos. Seus conceitos fundamentais continuam os mesmos: personalidade, direito subjetivo, dever jurídico, relação jurídica. No entanto, modificou-se a perspectiva através da qual são vistos.

Abandona-se a perspectiva puramente relativista, segundo a qual as pessoas seriam meros sujeitos de direito unidos pelo nexo de uma relação jurídica em que cada um teria direitos e deveres para com o outro. A novidade que o princípio da dignidade da pessoa humana trouxe para o Direito Privado é o reconhecimento do valor da pessoa como titular de sua própria esfera de personalidade, e não simplesmente como um pressuposto do conceito técnico de capacidade, como mero sujeito de direito (Martins-Costa, 2001, p. 184). 
Com a concepção de Direito adotada a partir da segunda metade do século $\mathrm{XX}$, as Constituições destacaram normas relativas aos direitos da personalidade, em seus textos, tais como o direito à intimidade, à honra, à imagem, ao nome. Criouse, dessa forma, um "direito geral da personalidade” (Larenz, 1978, p. 160; Wieacker, 1993, p. 606). Em princípio, o reconhecimento e a proteção de tais direitos não são inéditos. Eles foram previstos desde as primeiras declarações de direitos e foram tutelados no âmbito constitucional, penal e civil. Todavia, foi em razão dessa nova concepção que os direitos de personalidade foram incorporados e detalhados nos códigos civis e desenvolveram-se, notavelmente, na doutrina e na jurisprudência (Rivera, 1996, p. 13). ${ }^{2}$

Quanto à disciplina dos direitos da personalidade, ressalta-se o atributo da elasticidade, determinando que não há "numerus clausus" de hipóteses tuteladas, pois o valor protegido é a personalidade limitada tão somente pelos interesses de outras personalidades. Por conseguinte, a tutela aos direitos da personalidade deve ser estendida também às hipóteses juridi- camente relevantes que não estão previstas na lei (Perlingieri, 2001). Nessa linha, a doutrina e a jurisprudência reconheceram e vêm ampliando o conceito de dano moral, relacionando-o com a ideia de "danos à pessoa" em toda a sua esfera de personalidade, considerando-se a sua integridade psicossomática e existencial (Martins-Costa, 2001).

A nova concepção de Direito também modificou o entendimento do princípio da autonomia da vontade, o qual deixou de pressupor a igualdade e a liberdade meramente formais, considerando as limitações sociais e econômicas que diferenciam as pessoas, na vida em sociedade (Hesse, 1995, p. 78-79). Nesse sentido, destaca-se a aplicação do "princípio funcional"3 aos institutos de Direito Privado, como o reconhecimento da função social da propriedade e da função social do contrato. Os institutos necessários ao desenvolvimento social e econômico das pessoas devem ser dirigidos pela cooperação entre os grupos sociais, integrando a sociedade econômica com a ordem jurídica pública; pois, em um contexto de pluralismo social, tais institutos refletem na vida econômica de toda a sociedade, e não

\footnotetext{
2 Nesse sentido: o Código Civil português de 1966, o Código Civil boliviano de 1975, o Código Civil peruano de 1984, o Código Civil de Quebec de 1991, o Código Civil Argentino após a reforma de 1993 e o Código Civil brasileiro de 2002.

3 “Princípio funcional”, expressão usada por Wieacker (1993, p. 632).
} 
apenas na esfera jurídica dos sujeitos envolvidos (Wieacker, 1993, p. 632).

No mesmo sentido, destaca-se o reconhecimento da possibilidade da aplicação direta ou imediata das normas de direitos fundamentais aos casos de omissão ou de retrocesso da legislação ordinária de Direito Privado (Gutiérrez, 1995, p. 22) ${ }^{4}$, principalmente, quando há ameaça à liberdade pessoal em face do exercício do poder econômico ou social (Hesse, 1998, p. 286). Dessa forma, afasta-se a presumida oposição entre a aplicação mediata ou indireta e a aplicação imediata ou direta dos direitos fundamentais, enfatizando-se a importância da coordenação entre elas (Gutiérrez, 1995, p. 22).

Além disso, atualmente, algumas matérias são consideradas particularmente relevantes em razão de sua conotação social. Nesses casos, também ocorre restrição ao princípio da autonomia privada, negando-se a ideia de liberdade geral, salvo disposição legislativa em contrário. Parte-se de proibições genéricas enquanto pressupostos de medidas particulares que eventualmente as removam. Nesse sentido, salienta-se a proteção ao solo, ao meio ambiente, ao consumidor e à vida frente às novas tecnologias (intervenções artificiais como a genética, a reprodução assistida, os transplantes de órgãos, a interrupção voluntária da gravidez, o suicídio e a eutanásia) (Zagrebelsky, 1999, p. 35-36).

No ordenamento jurídico atual, percebe-se o desenvolvimento de uma relação de reciprocidade entre o Direito Constitucional e o Direito Privado. O Direito Constitucional possui as funções de garantia, de orientação e de impulso em relação ao Direito Privado. A Constituição protege os fundamentos e os institutos de Direito Privado formalmente abrigados em seu texto como matéria constitucional de eventuais supressões ou esvaziamentos através da legislação ordinária. Ademais, desempenha o papel de guia na evolução do Direito Privado, estabelecendo diretrizes ao seu desenvolvimento. Em contrapartida, o Direito Privado desenvolve os meios necessários ao desenvolvimento dos direitos fundamentais, possibilitando sua realização sobretudo no que concerne à liberdade da pessoa humana (Hesse, 1995, p. 81-88).

\section{CONSIDERAÇÕES FINAIS}

A tendência observada a partir do segundo pós-guerra, no sentido de atribuir conteúdo substancial ao

4 Nesse sentido, estão os seguintes julgados do STF: RE 160.222-8, RE 158.215-4, RE 161.243-6, RE 175.161-4, RE 201.819, HC 71.373-4. 
Direito, reconhecendo a dignidade da pessoa humana como principal fundamento do Estado e da ordem jurídica, ocasionou mudanças qualitativas em todos os ramos do Direito e, consequentemente, alterou as relações entre eles, se comparada com o modelo jurídico novecentista, vigente até o início do século XX.

A Constituição deixou de ser um diploma político direcionado, exclusivamente, à organização fundamental do Estado e ao estabelecimento das liberdades públicas. Passou a guardar os valores orientadores da vida social, transformando-se em diploma jurídico de nível normativo superior. Os direitos fundamentais deixaram de representar garantias individuais contra a Administração Pública, assumindo, também, a condição de conteúdos fundamentais da ordem jurídica. O Direito Privado, por sua vez, acompanhou tais mudanças, adequando seus institutos à transcendência desses preceitos fundamentais. Atualmente, observa-se o recuo perante o formalismo do sistema de Direito Privado clássico do século XIX; a relativização dos institutos de Direito Privado através do reconhecimento da sua função social; e a vinculação ético-social desses institutos.

Uma vez compreendidas as alterações desencadeadas pela concepção de Direito adotada a partir da segunda metade do século XX, cabe aos juristas mantê-la e atualizá-la. No desempenho de tal tarefa, é imprescindível reconhecer a posição e a importância de cada um dos ramos do Direito, mantendo o equilíbrio da ordem jurídica. Deve-se evitar, sobretudo, descaracterizá-los ou suprimi-los.

Nesse contexto, é evidente a abertura do Direito Privado às normas de Direito Constitucional, que inclusive se faz imprescindível à realização de um Estado de Direito radicado na dignidade da pessoa humana. Todavia, deve-se observar o melhor modo de realizá-la, pois não se pode aniquilar a tradição dos institutos jurídicos privados e deve-se garantir a segurança jurídica nas relações privadas, ressalvando-se a autonomia do Direito Privado enquanto ramo jurídico.

Propõe-se, portanto, a aplicação mediata ou indireta dos preceitos constitucionais como a forma mais adequada às particularidades da sua realização nas relações jurídicas privadas. Destaca-se que a Constituição não é "a origem do mundo, a célula jurídica germinal da qual tudo procede". ${ }^{5}$ Constitui a ordem jurídica fundamental do Estado, dispondo os aspectos mais importantes da vida estatal e social. Os demais aspectos são entregues ao encargo dos poderes

5 Observação irônica de Ernst Forsthoff (apud HESSE, 1995, p. 82). 
estatais constituídos por ela, especialmente ao legislador democrático (Hesse, 1995. p. 82).

Nesse processo, afasta-se a presumida oposição entre a aplicação mediata ou indireta e a aplicação imediata ou direta dos direitos fundamentais, enfatizando-se a importância de sua coordenação. Considerando-se a relevância atribuída aos direitos fundamentais, na ordem democrática atual, admite-se a aplicação direta ou imediata das normas de direitos fundamentais aos casos de omissão ou de retrocesso da legislação ordinária de Direito Privado, principalmente, quando há ameaça à liberdade pessoal em face do exercício do poder econômico ou social.

Deve-se considerar que, em uma ordem democrática e pluralista, os valores dispostos na Constituição representam propostas de soluções a serem desenvolvidas por deliberação. De modo algum constituem um projeto rigidamente ordenador com força própria a fim de impor seus comandos de cima para baixo (Zagrebelsky, 1999, p. 14; Souza Junior, 2005, p. 12). Por outro lado, deve-se entender que o Direito Privado que repousa sobre a proteção da personalidade e sobre a autonomia privada faz parte das condições fundamentais à realização da ordem constitucional democrática (Hesse, 1995, p. 86). Dessa forma, o reconhecimento da centralidade do conceito de pessoa como elemento da relação jurídica constitui, principalmente, uma visão integrada do ordenamento jurídico, reconhecendo a relação de reciprocidade existente entre o Direito Constitucional e o Direito Ordinário.

\section{REFERÊNCIAS}

BOBBIO, Norberto. Estado, governo e sociedade: para uma teoria geral da política. 4. ed. Rio de Janeiro: Paz e Terra, 1995a.

O positivismo jurídico: lições de filosofia do direito. São Paulo: Ícone, 1995b.

GUTIÉRREZ, Ignacio. Introdução. In: HESSE, Konrad. Derecho constitucional y derecho privado. Madrid: Civitas, 1995, p. 22.
HESSE, Konrad. Derecho constitucional y derecho privado. Madrid: Civitas, 1995.

Elementos de direito constitucional da República Federal da Alemanha. Porto Alegre: Sergio Antonio Fabris, 1998.

LARENZ, Karl. Derecho civil: parte general. Madrid: Editorial Revista de Derecho Privado, 1978. 
MARTINS-COSTA, Judith. Os danos à pessoa no direito brasileiro e a natureza da sua reparação. Revista da Faculdade de Direito da UFRGS, Porto Alegre, v. 19, p. 181-207, 2001.

PERLINGIERI, Pietro. Il diritto civile nella legalita constituzionale. Napoli: Edizioni Scientifiche Italiane, 2001.

RIVERA, Julio César. El derecho privado constitucional. Revista dos Tribunais, São Paulo, ano 85, n. 725, p. 11-28, mar. 1996.

SOUZA JUNIOR, Cezar Saldanha. Direito constitucional, direito ordinário, direito judiciário. Cadernos do Programa de PósGraduação em Direito. Porto Alegre, n. 3, p. 7-18, mar. 2005. - O tribunal constitucional como poder: uma nova teoria da divisão dos poderes. São Paulo: Memória Jurídica, 2002.

WIEACKER, Franz. História do direito privado moderno. 2. ed. Lisboa: Fundação Calouste Goulbenkian, 1993.

ZAGREBELSKY, Gustavo. El derecho dúctil: ley, derechos, justiça. 2. ed. Madrid: Trotta, 1999. 